\title{
Kajian Sedimentasi pada Muara Sungai Batang Arau Kota Padang
}

\author{
Tipani Ulfah Sabrina, Taufiq Hidayat, Hartati, Zahrul Umar \\ Politeknik Negeri Padang. \\ fani.sabrina06@gmail.com
}

\begin{abstract}
Abstrak
Sungai Batang Arau mempunyai panjang sungai $\pm 29,72 \mathrm{~km}$ dengan luas Daerah Aliran Sungai (DAS) $\pm 172 \mathrm{~km}^{2}$, hulu sungai berada pada puncak bukit Punggung Lading Kecamatan Lubuk Kilangan dan Gunung Gadut Kecamatan Pauh Kota Padang, dan pada daerah hilir terdapat Pelabuhan Muara. Pelabuhan Muara dibangun pertama kali pada abad ke-17 hingga awal abad ke-20. Saat ini pelabuhan Muara berfungsi sebagai pintu gerbang antar pulau terutama menuju ke Kepulauan Mentawai, Pulau Sikuai, dan sekitarnya, serta kembali lagi ke kota Padang.

Akhir-akhir ini fungsi pelabuhan di muara sungai Batang Arau tempat keluar masuknya kapal - kapal terganggu karena terjadinya pendangkalan sungai. Ini terjadi karena tingginya tingkat pertambahan penduduk sehingga mempengaruhi perubahan tata guna lahan dari hutan sekunder, kebun dan sawah menjadi kawasan permukiman, serta bertambah luasnya kawasan tambang batu kapur yang digunakan untuk dasar pembuatan semen oleh PT Semen Padang pada DAS Batang Arau yang mengakibatkan bertambahnya debit puncak run off, meningkatnya erosi dan konsentrasi sedimen di DAS Batang Arau.

Untuk menghitung angkutan sedimen di pelabuhan muara di DAS Batang Arau dilakukan dengan metoda Yang's dan metoda Engelund\& Hansen. Dari hasil perhitungan yang dilakukan dengan Metode Yang's didapat hasil 28703,83 ton/tahun dan dengan Metoda Engelund \& Hansen didapat hasil 34587,43 ton/tahun. Dan untuk estimasi tebal endapan di pelabuhan Muara Batang Arau kota Padang didapat dari hasil kajian angkutan sedimen yang berdasarkan angkutan sedimen terbesar Metoda Engelund \& Hansen hasilnya adalah 21,64 cm per tahun.
\end{abstract}

Kata Kunci : angkutan sedimen, erosi, tebal endapan.

\section{PENDAHULUAN}

Secara geografis, DAS Batang Arau kota Padang terletak pada $0^{\circ} 48^{\prime \prime}$ sampai dengan $0^{\circ} 56^{\prime \prime} L S$ dan $100^{\circ} 21$ sampai dengan $100^{\circ} 33^{\prime \prime} \mathrm{BT}$, dengan ketinggian 0 sampai dengan $1.210 \mathrm{~m}$ dari permukaan laut (dpl). Secara administrasi, sebelah utara berbatasan dengan DAS Batang Kuranji, sebelah selatan berbatasan dengan DAS Timbalun dan DAS Batang Tarusan, sebelah timur berbatasan 
dengan Kabupaten Solok dan sebelah barat : berbatasan dengan Samudera Indonesia.

Sungai Batang Arau mempunyai panjang sungai $\pm 29,72 \mathrm{~km}$ dengan luas Daerah Aliran Sungai (DAS) $\pm 172 \mathrm{~km}^{2}$, hulu sungai berada pada puncak bukit Punggung Lading Kecamatan Lubuk Kilangan dan Gunung Gadut Kecamatan Pauh Kota Padang, dan pada daerah hilir terdapat Pelabuhan Muara. Pelabuhan Muara dibangun pertama kali pada abad ke-17 hingga awal abad ke-20. Saat ini pelabuhan Muara berfungsi sebagai pintu gerbang antar pulau terutama menuju ke Kepulauan Mentawai, Pulau Sikuai, dan sekitarnya, serta kembali lagi ke kota Padang

Akhir-akhir ini daerah hulu terjadi pengurangan luas tutupan hutan karena adanya pembukaan lahan-lahan hutan untuk ladang (pertanian lahan kering) berpindah dan maraknya penebangan liar, pertambahan penduduk yang mencapai 2 sampai 3 kali lipat sehingga penduduk mulai membuka lahan hutan untuk pertanian, karena sebagian lahan pertanian produktif telah dijadikan pemukiman, perkantoran dan lahan usaha, industri dan jasa, serta bertambah luasnya kawasan tambang batu kapur yang digunakan dasar pembuatan semen oleh PT Semen Padang pada DAS Batang Arau.

Akibat penurunan luas tutupan lahan daerah hulu, maka terjadi kecenderungan peningkatan debit maksimum, sehingga secara keseluruhan fungsi lahan sebagai penahan aliran permukaan semakin menurun, dan menyebabkan penurunan infiltrasi dan perkolasi serta meningkatkan aliran permukaan. Peningkatan aliran permukaan pada musim hujan akan menyebabkan peningkatan debit maksimum, peningkatan erosi dan konsentrasi sedimentasi di bagian DAS hilir sehingga menyebabkan pendangkalan di daerah muara sungai Batang Arau

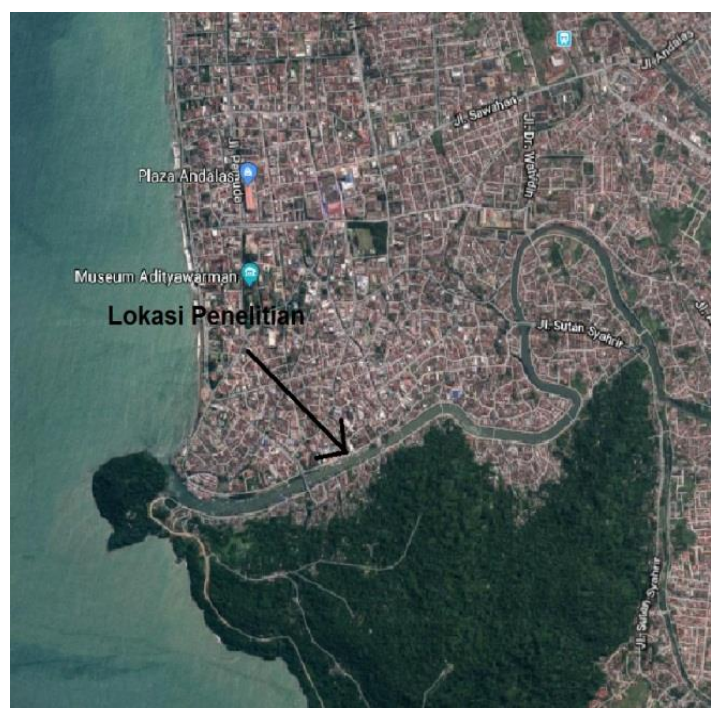

\section{Gambar 1 Lokasi Studi}

\section{Analisis rerata hujan kawasan}

Analisis hidrologi untuk menentukan rerata hujan kawasan ada beberapa metode yaitu metode aritmatik, metode poligon thiessen dan metode Isohyet. Pada penelitian ini digunakan metode Poligon Thiessen sebagai berikut :

$P=\frac{(A 1 P 1)+(A 2 \cdot P 2)+\cdots+\left(A_{n} P n\right)}{A 1+A 2+\cdots+A n}$

Dengan :

$\mathrm{P}=$ hujan rerata kawasan

$\mathrm{P}_{1}, \mathrm{P}_{2}, \mathrm{P}_{3}=$ hujan pada stasiun $1,2,3 \ldots, \mathrm{n}$

$A_{1}, A_{2}, A_{3}=$ luas daerah yang mewakili stasiun $1,2,3 \ldots n$

\section{Analisis Frekuensi}

Analisis frekuensi bertujuan untuk mencari hubungan besarnya suatu kejadian ekstrem terhadap frekuensi kejadian berdasarkan distribusi probabilitas. Beberapa jenis distribusi 
frekuensi yang digunakan yaitu Metoda Distribusi Gumbel, Normal, Log Normal dan Gumbel.

Setelah selesai analisis distribusi probabilitas dengan ke empat metode tersebut, maka dilakukan uji distribusi probabilitas dengan metoda Smirnov Kolmogorov dan Metoda Chi-Kuadrat. Uji distribusi probabilitas dimaksudkan untuk mengetahui apakah persamaan distribusi probabilitas yang dipilih dapat mewakili distribusi sampel data yang dianalisis.

\section{Analisis Debit Banjir Rancangan}

Beberapa metode debit banjir rancangan yang dikembangkan berdasarkan karakteristik DAS dan sebaran hujan. Metode yang digunakan antara lain :

a. Metode Hasper

$$
\mathrm{Qp}=\alpha \times \beta \times \mid \times A \text {.......(2) }
$$

b. Metode Melchior

$$
\mathrm{Qp}=\alpha \times \mathrm{x} \mid \times \mathrm{A} \ldots \ldots . .
$$

c. Metode Nakayasu

$$
\mathrm{Qp}=\mathrm{C} \times \frac{1}{3.6} \times \mathrm{A} \times \frac{\mathrm{R}_{0}}{0.3 \times \mathrm{tp}+\mathrm{t} 0.3} \ldots
$$

Dimana :

$\mathrm{Qp}=$ Debit maksimum $\left(\mathrm{m}^{3} / \mathrm{dt}\right)$

$\mathrm{A}=$ Koefisien pengaliran

$\mathrm{B}=$ Koefisien reduksi

I = Intensitas hujan $\left(\mathrm{m}^{3} / \mathrm{dt} / \mathrm{km}^{2}\right)$

$A=$ Luas daerah pengaliran $\left(\mathrm{km}^{2}\right)$

$\mathrm{C}=$ Koefisien pengaliran

$\mathrm{A}=$ Luas daerah pengaliran $\left(\mathrm{km}^{2}\right)$

Ro = Curah hujan satuan $(\mathrm{mm})$

$\mathrm{t}_{\mathrm{p}} \quad=$ Tenggang waktu dari permulaan hujan sampai puncak banjir (jam)

$\mathrm{t}_{0.3}=$ Waktu yang diperlukan pada penurunan debit puncak sampai ke debit sebesar $30 \%$ dari puncak (jam)

\section{AngkutanSedimen}

Ada tiga macam angkutan sedimen yang terjadi di dalam alur sungai (Mulyanto, 2007) yaitu :

a. Bed load transport yaitu peng- angkutan material terjadi pada aliran yang berkecepatan relative lambat, sehingga material yang terbawa arus bersifat menggelinding sepanjang saluran.

b. Saltation load transport yaitu pengangkutan material terjadi pada aliran berkecepatan relative cepat, sehingga material yang terbawa arus membuat loncatan-loncatan akibat dari gaya dorong pada material tersebut.

c. Suspended load transport yaitu Jika kecepatan aliran semakin cepat, gerakan loncatan material akan semakin sering terjadi sehingga apabila butiran tersebut tergerus oleh aliran utama atau aliran turbulen kearah permukaan, maka material tersebut tetap bergerak (melayang) didalam aliran dalam selang waktu tertentu.

\section{Analisis Angkutan Sedimen Total}

Angkutan sedimen total dapat dianggap sebagai penjumlahan bed load $\left(\mathrm{T}_{\mathrm{b}}\right)$ dan suspended load $\left(\mathrm{T}_{\mathrm{s}}\right)$, cara penjumlahan ini dipakai oleh Einstein. Dan Chih Ted Yang (1996) dalam buku Sedimen Transport Theory and Practice perhitungan angkutan sedimen total terdiri dari metode : a) Yang (1973) ; b) Ackers dan White (1973) ; c) Engelund dan Hansen (1967) ; d) Shen dan Hung (1972) ; e) Colby (1955) ; f) Bagnold (1966) ; g) Laursen (1985).

Dalam makalah ini penulis hanya menyajikan 2 metode yaitu : 


\section{a. Metode Yang (1973)}

$\log C t=5,435-0,286 \log \frac{\omega d}{\vartheta}-0,457 \log \frac{\mathrm{U} *}{\omega}+$ $\left(1,799-0,409 \log \frac{\omega d}{\vartheta}-\right.$

$\left.0,314 \log \frac{\mathrm{U} *}{\omega}\right) \log \left(\frac{\mathrm{V} . \mathrm{S}}{\omega}-\frac{\mathrm{Vcr}}{\omega}\right.$.S..

Dimana $: \mathrm{Ct}=$ Total konsentrasi sedimen (PPM ; mg/tt)

$\frac{V c r}{\omega}=\frac{2,5}{\log \left(\frac{U^{* d}}{\partial}\right)-0,06}+0,66$ untuk $1,2<\frac{U^{*} d}{\partial}<70$

$\frac{\mathrm{Vcr}}{\omega}=2,05$ untuk $70 \leq \frac{\mathrm{U}^{*} \mathrm{~d}}{\partial}$

Dimana :

$\mathrm{Ct}=$ Konsentrasi sedimen total $(\mathrm{mg} / \mathrm{t})$

$\omega=$ Kecepatan jatuh sedimen (ft/sec)

$\mathrm{d}=$ Diameter tengah partikel $(\mathrm{ft})$

$\vartheta \quad=$ Viskositas kinematik $\left(\mathrm{ft}^{2} / \mathrm{sec}\right)$

$\mathrm{U}^{*}=$ Kecepatan geser $(\mathrm{ft} / \mathrm{sec})$

$\mathrm{Vcr}=$ Kecepatan kritis (ft/sec)

$\mathrm{S}=$ Kemiringan sungai

$\mathrm{V}=$ Kecepatan aliran (ft/sec)

\section{b. Metode Engelund dan Hansen (1967)}

$q s=0,05$ ys. $V^{2}\left[\frac{d}{g\left(\frac{y s}{\gamma}-1\right)}\right]^{\frac{1}{2}}\left[\frac{T_{0}}{(y s-\gamma) d}\right]^{\frac{3}{2}}$

$\mathrm{T}_{0}=\mathrm{y} \times \mathrm{D} \times \mathrm{S}$

Qs $=W \times q s$

$G w=y \times W \times D \times V$

$\mathrm{Cs}=\frac{\mathrm{Qs}}{\mathrm{Gw}}$

Dimana :

$\mathrm{V}=$ Kecepatan aliran (ft/s)

$\mathrm{d}=$ Diameter tengah partikel $(\mathrm{ft})$

$\mathrm{g}=$ Gravitasi $\left(\mathrm{ft}^{2} / \mathrm{sec}\right)$

$\mathrm{ys}=$ Massa jenis sedimen $\left(\mathrm{lb} / \mathrm{ft}^{3}\right)$

$\mathrm{T}_{0}=$ Tegangan geser $\left(\mathrm{lb} / \mathrm{ft}^{2}\right)$

$\mathrm{\gamma w}=$ Massa jenis air $\left(\mathrm{lb} / \mathrm{ft}^{3}\right)$

$\mathrm{D}=$ Kedalaman sungai $(\mathrm{ft})$

$S=$ Kemiringan sungai

$\mathrm{W}=$ Lebar sungai $(\mathrm{ft})$
$\mathrm{Qs}=$ Muatan sedimen $(\mathrm{lb} / \mathrm{sec})$

$\mathrm{Cs}=$ Konsentrasi sedimen total $(\mathrm{mg} / \mathrm{t})$

Untuk perhitungan selanjutnya adalah memilih hasil maksimum dari kedua metoda angkutan sedimen di atas dan membandingkan hasilnya dengan perkiraan besarnya erosi yang terjadi dalam Daerah Aliran Sungai (DAS) menggunakan model USLE (Universal Soil Loss Equation) dari USDA (United States Departement of Agriculture) untuk memperkirakan besarnya erosi permukaan suatu DAS (Ditjen Sumber Daya Air, 2003). Faktor yang mempengaruhi meliputi faktor erosivitas hujan, erodibilitas tanah, kemiringan dan panjang lereng, jenis penutup lahan dan pengolahan tanah.

Untuk menghitung tingkat erosi atau jumlah tanah yang hilang adalah sebagai berikut:

$$
A=R \times K \times L S \times C \times P
$$

Dimana :

A = Jumlah tanah yang hilang (ton/ha/tahun)

$\mathrm{R}=$ Erosivitas hujan rata-rata

$\mathrm{K}=$ Indeks erodibilitas tanah

LS = Indeks panjang dan kemiringan lereng

$\mathrm{C}=$ Indeks pengelolaan pertanian

$\mathrm{P}=$ Indeks upaya konservasi tanah

Sedimen yang terbawa oleh sungai lebih sedikit dibandingkan dengan erosi total dari DAS yang ditinjau, besarnya sedimen yang terbawa oleh aliran sungai disebut juga Yield (hasil) merupakan perkalian antara SDR (Sediment Delivery Ratio) dengan erosi total ( $\left.\mathrm{A}_{\mathrm{T}}\right)$ dari DAS tersebut. Rasio pengantaran sedimen tergantung dari luas DAS dan erosi total $\left(A_{T}\right)$ atau dengan rumus :

$$
\mathrm{Y}=\mathrm{A}_{\mathrm{T}} \times \mathrm{SDR}
$$


(A dalam $\mathrm{km}^{2}$ ) (Kodoatie R.J dan Sjarief.R., 2008)

\section{METODE PENELITIAN}

Metode penelitian ini dilakukan pada DAS Batang Arau di pelabuhan muara, dengan mengumpulkan data primer dan data sekunder. Data Primer adalah data yang didapat langsung dari lapangan, dengan cara peninjauan langsung ke lokasi penelitian seperti foto dokumentasi sungai, kedalaman aliran ,penampang melintang sungai dan pengambilan sampel sedimen tahun 2018. Data Sekunder adalah data topografi Sungai Batang Arau, peta tataguna lahan dan data curah hujan tahun 2013-2015 dari BWSS V.

Dan selanjutnya dilakukan :

1.Analisis hidrologi dengan luaran curah hujan rencana dan debit banjir rencana

2.Analisis butiran sedimen di laboratorium

3.Analisis angkutan sedimen

5.Analisis tebal endapan sedimen

\section{HASIL DAN PEMBAHASAN}

\section{Analisis uji distribusi probabalitas}

Hasil analisis rerata hujan kawasan dengan metode Poligon, datanya dipakai untuk analisis distribusi probabilitas . Rekapitulasi hasil analisis distribusi probabilitas sebagai berikut :

Tabel 1.Hasil Analisis Distribusi Probabilitas

\begin{tabular}{|c|c|c|c|c|}
\hline \multirow{2}{*}{$\begin{array}{c}\text { Periode } \\
\text { Ulang }\end{array}$} & \multicolumn{4}{|c|}{ Hujan Rencana Harian Maksimum } \\
\cline { 2 - 5 } & \multicolumn{4}{|c|}{ Metode Distribusi Probabilitas } \\
\cline { 2 - 5 } & Normal & Log Normal & Gumbel & Log Pearson Tipe III \\
\hline 2 & 155,33 & 149,44 & 146,60 & 154,69 \\
\hline 5 & 191,54 & 191,93 & 198,25 & 192,91 \\
\hline 10 & 210,50 & 218,82 & 230,69 & 212,58 \\
\hline 25 & 226,02 & 243,59 & 268,52 & 232,81 \\
\hline 50 & 243,69 & 275,24 & 302,08 & 245,27 \\
\hline
\end{tabular}

Kemudian ke empat metode tersebut diuji distribusi probabilitas dengan Chi Kuadrat dan Smirnov Kolmogorov dan yang dapat diterima setelah diuji dengan ke dua metoda tersebut adalah dengan Metode Normal.

\section{Analisis Debit Banjir Rancangan}

Selanjutnya data curah hujan dengan metoda normal dipakai untuk analisis debit banjir rencana dengan beberapa periode ulang sebagai berikut :

Tabel 2. Rekapitulasi Perhitungan Debit Banjir Rencana

\begin{tabular}{|c|c|c|c|}
\hline \multirow{2}{*}{$\begin{array}{c}\text { Periode } \\
\text { Ulang } \\
\text { (tahun) }\end{array}$} & \multicolumn{3}{|c|}{ Debit banjir rencana } \\
\cline { 2 - 4 } & $\begin{array}{c}\text { Hasper } \\
\text { (m3/det) }\end{array}$ & $\begin{array}{c}\text { Melchior } \\
\text { (m3/det) }\end{array}$ & $\begin{array}{c}\text { Nakayasu } \\
\text { (m3/det) }\end{array}$ \\
\hline 2 & 362,740 & 368,284 & 434,76 \\
\hline 5 & 447,295 & 454,131 & 536,11 \\
\hline 10 & 491,586 & 499,099 & 589,11 \\
\hline 25 & 527,584 & 535,891 & 623,63 \\
\hline 50 & 569,095 & 577,793 & 682,09 \\
\hline
\end{tabular}

Dari ketiga metoda analisis debit rancangan, debit yang akan dipakai untuk tahap analisis selanjutnya adalah dengan metoda Nakayasu dengan periode ulang 2 tahun.

\section{Analisis Karakteristik Sedimen}

Pemeriksaan analisis sampel sedimen di laboratorium ini bertujuan untuk menentukan ukuran butira sedimen dan berat jenis sedimen. Untuk mendapatkan ukuran butiran $\mathrm{D}_{35}, \mathrm{D}_{50}$ dan $D_{90}$ langsung diplot pada grafik hubungan antara ukuran saringan dan komulatif persentase lolos (Gambar 1).

Berdasarkan gambar 1 dibawah diperoleh $\mathrm{D}_{35}=0,12 \mathrm{~mm}, \mathrm{D}_{50}=0,25 \mathrm{~mm}$ dan $\mathrm{D}_{90}=0,38$ $\mathrm{mm}$. 


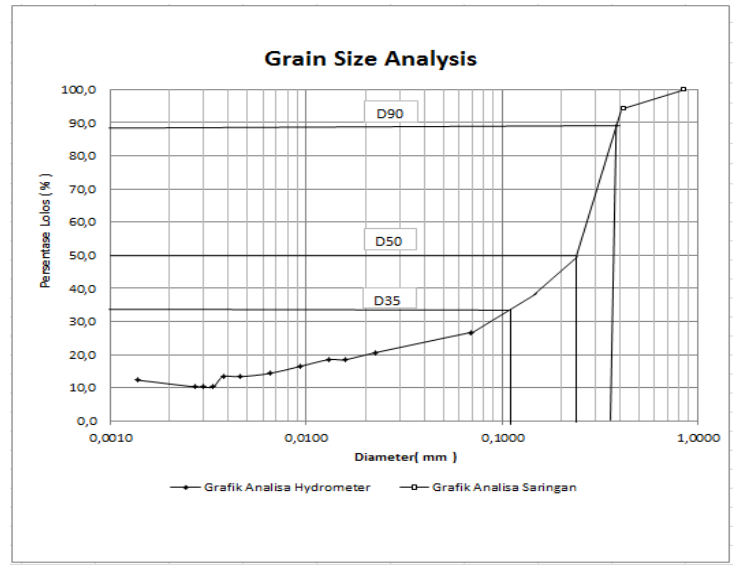

Gambar 1. Hubungan antara ukuran saringan dan komulatif lolos

\section{Analisis Angkutan Sedimen Total}

Untuk analisis ini data debit yang digunakan adalah debit maksimum yaitu dengan periode ulang 2 tahunan yang diperoleh dari perhitungan debit banjir menggunakan Metode Nakayasu yaitu 434,76 $\mathrm{m}^{3} / \mathrm{dt}$. Angkutan sedimen total dihitung dengan menggunakan Metode Yang, dan Engelund \& Hansen.

Hasil analisis angkutan sedimen dengan Metode Yang, dan Engelund \& Hansen tertera pada tabel 3.

Tabel 3. Rekapitulasi Angkutan Sedimen Total

\begin{tabular}{|c|c|c|}
\hline \multirow{2}{*}{$\begin{array}{c}\text { Periode } \\
\text { Ulang } \\
\text { (tahun) }\end{array}$} & \multicolumn{2}{|c|}{$\begin{array}{c}\text { Metode Angkutan Sedimen } \\
\text { Total (ton/tahun) }\end{array}$} \\
\cline { 2 - 3 } & Yang's & $\begin{array}{c}\text { Engelund } \\
\text { and Hansen }\end{array}$ \\
\hline 2 & 362,740 & 34587.427 \\
\hline 5 & 447,295 & 39913.701 \\
\hline 10 & 491,586 & 42527.465 \\
\hline 25 & 527,584 & 44667.941 \\
\hline 50 & 569,095 & 47047.962 \\
\hline
\end{tabular}

\section{Analisis erosi dengan Metode USLE}

Dengan diketahui :
1) Indeks erodibiltas tanah (K) diambil sebesar 0,11 (tanah regosol yang bahan induknya batu liat berkapur)

2) Faktor panjang dan kemiringan lereng (LS), diambil sebesar 1,4 (kemiringan lereng 8$15 \%)$

3) Indeks pengelolaan tanaman (C), diambil sebesar 0,5 (kebun campuran dengan kerapatan rendah)

4) Indeks upaya pengelolaan (P), diambil 0,75 (pengelolaan tanah dan penanaman menurut garis kontur kemiringan 9-20\%)

5) Indeks Erosivitas Curah Hujan (R) untuk periode hujan 2003 - 20155 didapat $R$ ratarata 533,94

Maka besaran erosi yang terjadi pada muara DAS Batang Arau dengan luas DAS $=172 \mathrm{~km}^{2}$ adalah :

$$
\begin{aligned}
& A=R \times K \times L S \times C \times P \\
& A=535,94 \times 0,11 \times 1,4 \times 0,5 \times 0,75=30,95 \\
& \text { ton/ha/tahun }
\end{aligned}
$$

Sehingga besaran erosi adalah sebagai berikut

$A_{\text {das }}=30,95 \times 17200=532350,77$ ton $/$ tahun Dan yang diperkirakan masuk kesungai " $Y$ 'hasil adalah :

$\operatorname{SDR}=0,41 \times\left(A_{d a s}\right)^{-0,3}=0,41 \times(172)^{-0,3}=$ 0,087524

Y'hasil $=0,087524 \times 532350,77=46593,27$ ton/tahun

\section{Analisis sedimentasi}

Analisis angkutan sedimen total didapat dengan mengkonversi endapan sedimen yang masih dalam satuan $\mathrm{mg} / \mathrm{l} \mathrm{ke} \mathrm{ton/tahun,} \mathrm{maka,}$ hasilnya sebagai berikut:

Diketahui panjang sungai Batang Arau dan anak sungai utamanya $=86.660 \mathrm{~m}$, 
lebar sungai rata-rata $=40 \mathrm{~m}$, dan kedalaman air rata-rata $(b)=2,31 \mathrm{~m}$, maka volume air sungai adalah $=86.660 \times 40 \times 2,31=8.007 .384$ $\mathrm{m}^{3}=8.007 .384 .000$ liter

Dan hasil berat Sedimen yang sudah dikonversi ke ton per tahun terlihat pada Tabel 4:

Tabel 4. Berat sedimen untuk metoda Yang'S dan Metoda Engelund Hansen

\begin{tabular}{|c|c|c|c|c|}
\hline \multirow{2}{*}{$\begin{array}{l}\mathrm{N} \\
\mathrm{O}\end{array}$} & \multirow[t]{2}{*}{ Metode } & \multirow{2}{*}{$\begin{array}{c}\text { Vol. Air } \\
\text { Sungai (It) }\end{array}$} & \multicolumn{2}{|c|}{ Berat Sedimen } \\
\hline & & & $\mathrm{Mg} / \mathrm{tt}$ & Ton/thn \\
\hline 1 & Yang'S & $\begin{array}{l}8007384000.0 \\
0\end{array}$ & $\begin{array}{l}3584 . .6 \\
7\end{array}$ & $\begin{array}{l}28703.8 \\
3\end{array}$ \\
\hline 2 & $\begin{array}{l}\text { Engelun } \\
\text { d \& \& } \\
\text { Hansen }\end{array}$ & $\begin{array}{l}8007384000.0 \\
0\end{array}$ & 4319.44 & $\begin{array}{l}34587.4 \\
3\end{array}$ \\
\hline
\end{tabular}

Dari Tabel 4, terlihat berat sedimen dengan metode Engelund dan Hansen hasilnya paling mendekati dengan yield (hasil) erosi tanah yang hilang, $Y=46593,27$ ton/tahun. Selanjutnya untuk perhitungan tebal endapan yang terjadi di Muara Batang Arau, hasil digunakan adalah angkutan sedimen dengan metode Engelund \& Hansen.

Analisis tebal endapan dengan data-data pendukung yang diketahui seperti data kurva air balik $1755 \mathrm{~m}$, massa jenis $(\mathrm{ys})=2,53$, Porositas $(\varepsilon)=0,4$ (Breusers.H.N.C, 1988) dan Lebar sungai $=60 \mathrm{~m}$, maka tebal endapan di pelabuhan muara adalah sebagai berikut:

a. Volume sedimen padat $=34587,43 / 2,53=$ $13670,9 \mathrm{~m}^{3}$

b. Volume sedimen total $=\frac{13670,9}{1-0,4}$ $=22784,9 \mathrm{~m}^{3}$

c. Luas penampang sungai $=1755 \times 60=105300 \mathrm{~m}^{2}$ d. Tebal endapan

$=\frac{22784,9}{105300}$

$=0,2164 \mathrm{~m}=21,64 \mathrm{~cm}$

\section{KESIMPULAN DAN SARAN}

\section{Kesimpulan}

1. Debit banjir yang terjadi di DAS Batang Arau untuk periode ulang 2 tahun adalah $434,76 \mathrm{~m}^{3} / \mathrm{dt}$.

2. Besar angkutan sedimen dengan metode Yang's adalah $3584,671 \mathrm{mg} / \mathrm{lt}$ atau setara dengan 28703,835 ton/tahun, dan dengan metode Engelund \& Hansen adalah $4319,442 \mathrm{mg} / \mathrm{lt}$ atau setara dengan 34587,427 ton/tahun.

3. Besar erosi yang terjadi dengan metoda USLE adalah 532350,77 ton/tahun dan yang diperkirakan masuk kesungai adalah 46593,27 ton/tahun.

4. Hasil kajian angkutan sedimen Metode Engelund \& Hansen dipakai untuk menganalisis tebal endapan di pelabuhan Muara Batang Arau adalah 21,64 cm per tahun.

\section{Saran}

1. Hasil dari penelitian ini menjadi masukan untuk pihak terkait untuk melakukan pengendalian erosi pada DAS Batang Arau dengan melakukan konservasi tanah secara agronomis, mekanis dan secara kimia.

2. Hasil penelitian ini menjadi masukan untuk perlu dibangun chekdam atau tampungan sementara sebelum air buangan atau limbah galian tambang masuk ke DAS Batang Arau.

3. Sebaiknya dilakukan pembuangan sedimen minimal sekali dalam 3 tahun, untuk kelancaran keluar masuknya kapal di Pelabuhan Muara Padang. 
4. Melakukan penelitian terkait dengan melakukan tinjauan aspek lain seperti pengaruh air pasang surut air laut dll.

\section{DAFTAR PUSTAKA}

Asdak.C., 2002. Hidrologi dan Daerah aliran sungai. Gajah Mada University Prees, Yogyakarta.

Bambang Triatmojo,2008.Hidrologi Terapan. Gajah Mada University Prees, Yogyakarta.

Breusers.H.N.C., 1988. Lecture notes on sediment transport 1. Inertnational course in hydraulic engineering, Delft 1988.

Departemen Permukiman dan Prasarana Wilayah, Dit-jen Sumber Daya Air, 2003. Pedoman Pengelolaan Kerusakan Lingkungan DAS.

Gandakoesoema, 1970. Hidrolika, halaman 131. Penerbit Sumur, Bandung.

Kodoatie, R.J dan Sjarif.R, 2008. Pengelolaan Sumber Daya Air Terpadu Edisi 2, Penerbit Andi, Yogyakarta.

Kamiana, I Made, 2011. Teknik Perhitungan Debit Banjir Rencana Bangunan Air, Penerbit Graha Ilmu, Yogyakarta.

Mulyanto H.R., 2007. Sungai danSifat-sifatnya, PenerbitGrahallmu, Yogyakarta.

Nikken Consultan's.Inc 2001. Additional Consulting services on detailed design of Anai-Kandis River improvement in Padang flood control project.

Siswoko, 2010. Upaya mengatasi banjir secara menyeluruh, 